\section{Commentary: Ground glass opacity: Is it the Holy Grail?}

\author{
Alessandro Brunelli, MD
}

The current staging system does not distinguish between tumors with and without the presence of ground-glass opacity (GGO). This study from Watanabe and colleagues ${ }^{1}$ represents a critical appraisal of this concept: any tumor with a solid component smaller than $3 \mathrm{~cm}$ but with even a small GGO component has a better long-term prognosis compared with purely solid ones. Accordingly, c-Stage IA non-small cell lung cancer should be evaluated separately for tumors with GGO and pure-solid tumors.

The 5-year overall survival (OS) in those patients with c-stage IA 2 and IA 3 was $92 \%$ and $93 \%$, respectively. These positive results reflect a less-aggressive biologic behavior compared with pure solid tumors, which likely is the result of their different biogenesis.

Some data presented in the study tables deserve to be highlighted. Part-solid tumors were almost exclusively adenocarcinoma ( $99 \%$ of cases), with a lower maximum standardized uptake value ( 2.8 vs 6.2 ), a lower incidence of lymphatic (13\% vs $40 \%$ ) and vascular (12\% vs $45 \%$ ) infiltration, and reduced spread to hilar (5\% vs $10 \%)$ or mediastinal ( $4 \%$ vs $11 \%$ ) lymph nodes. In addition, nearly $60 \%$ of them displayed EGFR mutations (vs $26 \%$ of pure solid tumors).

Even a small GGO component in a predominantly solid tumor represents a surrogate characteristic indicating a less-aggressive cancer. If confirmed by other studies, the clinical implications of this finding are important for our daily practice. First of all, the next edition of the tumornode-metastasis classification should acknowledge the

\footnotetext{
From the Department of Thoracic Surgery, St James's University Hospital, Leeds, United Kingdom.

Disclosures: The author reported no conflicts of interest.

The Journal policy requires editors and reviewers to disclose conflicts of interest and to decline handling or reviewing manuscripts for which they may have a conflict of interest. The editors and reviewers of this article have no conflicts of interest.

Received for publication Dec 23, 2020; revisions received Dec 23, 2020; accepted for publication Dec 23, 2020; available ahead of print Jan 10, 2021

Address for reprints: Alessandro Brunelli, MD, Department of Thoracic Surgery, St James's University Hospital, Bexley Wing, Beckett St, Leeds, LS9 7TF, United Kingdom (E-mail: alexit_2000@yahoo.com).

J Thorac Cardiovasc Surg 2022;163:802-3

0022-5223/\$36.00

Copyright (C) 2021 by The American Association for Thoracic Surgery

https://doi.org/10.1016/j.jtcvs.2020.12.120
}

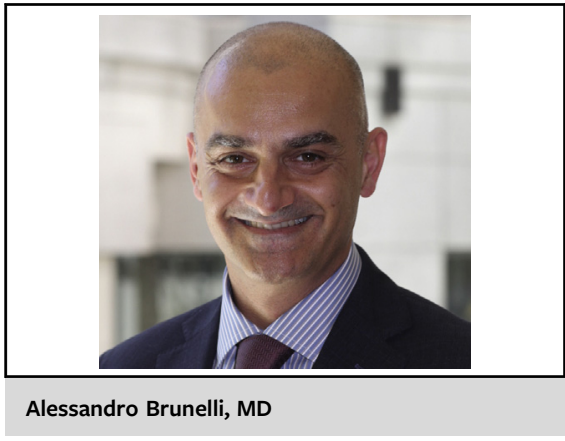

CENTRAL MESSAGE

The presence of a ground-glass opacity component is associated with better survival regardless of the size of the solid part. These tumors should be staged differently compared with pure-solid ones.

presence of a GGO component and stage these tumors differently compared with pure-solid ones. The maximum tumor size of the solid part does not necessarily stratify well prognosis in those tumors with GGO (a feature that should be regarded instead as an additional T descriptor).

This is corroborated by the finding that the $\mathrm{cT}$ categories stratified well OS and recurrence-free survival only in patients with pure solid tumors but not in the predominantly solid ones (where all cT categories had an OS greater than $90 \%$ ).

Second, if the presence of GGO translates into a lessaggressive biologic behavior, even for predominantly solid tumor, should we change the current paradigm of surgical indications for sublobar resections? Current guidelines recommend anatomic segmentectomies in pure GGO or partly solid tumors smaller than $2 \mathrm{~cm}^{2}$ Would this recommendation be applicable to predominantly solid tumors as well? This would seem the case according to the $93 \%$ OS found in patients undergoing sublobar resections $(81 \%$ anatomic segmentectomies) in predominantly solid c-stage IA2 (vs $72 \%$ of those with solid tumors). Although the numbers are very small and most patients have compromised cardiopulmonary function, even in those with predominantly solid c-stage IA3, the OS was $75 \%$ following sublobar resections.

Finally, if the presence of even a small GGO component is so "protective" in c-stage I non-small cell lung cancer, 
would this feature be associated with similar benefit in patients with larger tumors?

The authors should be commended for conducting this relevant and timely investigation, which may prove to be a pivotal study to change our staging and curative approach to patients with lung cancer displaying this radiologic characteristic.

\section{References}

1. Watanabe Y, Hattori A, Nojiri S, Matsunaga T, Takamochi K, Oh S, et al. Clinica impact of a small component of ground-glass opacity in solid-dominant clinical stage IA non-small-cell lung cancer. J Thorac Cardiovasc Surg. 2022;163: 791-801.e4.

2. Howington JA, Blum MG, Chang AC, Balekian AA, Murthy SC. Treatment of stage I and II non-small cell lung cancer: diagnosis and management of lung cancer, 3rd ed: American College of Chest Physicians evidence-based clinical practice guidelines. Chest. 2013;143(5 suppl):e278S-313S.
See Article page 791.

\section{Commentary: The ground-glass opacity: "The savior" for lung cancer?}

Ting Ye, MD, $\mathrm{PhD}$, and Haiquan Chen, $\mathrm{MD}, \mathrm{PhD}$

Watanabe and colleagues' study ${ }^{1}$ showed that part-solid lung cancer with a minor ground-glass opacity (GGO) component $(\leq 25 \%)$ had better recurrence-free survival and overall survival than pure-solid lung cancer. Their results are consistent with previous findings that a GGO component is a favorable prognostic predictor for lung cancer. $^{2,3}$ Clinically, subsolid and pure-solid lung cancer exhibit quite different natural courses. The natural evolution of subsolid nodules may be from pure GGO nodule to partsolid nodule, and eventually to pure-solid one, whereas pathologically preinvasive lesions (atypical adenomatous hyperplasia or adenocarcinoma in situ/minimal invasive adenocarcinoma) evolve to invasive adenocarcinoma. Although the evolution is sometimes slow, the actual growing pace of the GGO is uneven and unpredictable. In contrast, pure-solid tumors grow rapidly, and very small

\footnotetext{
From the Department of Thoracic Surgery, Shanghai Cancer Center, Department of Oncology, Shanghai Medical College, Institute of Thoracic Oncology, and State Key Laboratory of Genetic Engineering, School of Life Sciences, Fudan University, Shanghai, China.

Disclosures: The authors reported no conflicts of interest.

The Journal policy requires editors and reviewers to disclose conflicts of interest and to decline handling or reviewing manuscripts for which they may have a conflict of interest. The editors and reviewers of this article have no conflicts of interest.

Received for publication Dec 27, 2020; revisions received Dec 27, 2020; accepted for publication Dec 28, 2020; available ahead of print Jan 8, 2021.

Address for reprints: Haiquan Chen, MD, PhD, 270 Dong'an Rd, Shanghai, China, 200032 (E-mail: hqchen1@yahoo.com).

J Thorac Cardiovasc Surg 2022;163:803-4 0022-5223/\$36.00

Copyright (c) 2021 Published by Elsevier Inc. on behalf of The American Association for Thoracic Surgery

https://doi.org/10.1016/j.jtcvs.2020.12.117
}

Check for updates

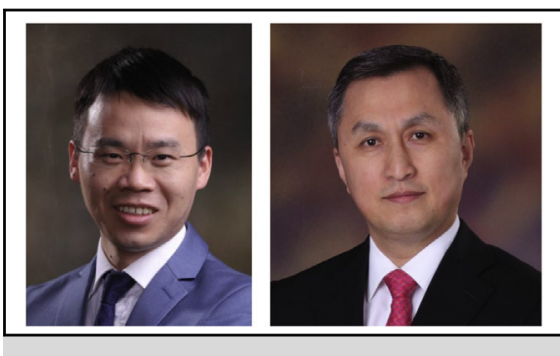

Ting Ye, MD, PhD, and Haiquan Chen, MD, PhD

\section{CENTRAL MESSAGE \\ Solid-predominant lung cancers \\ have a lymphatic metastasis rate \\ of $9 \%$; more invasive surgical \\ extent including systemic lymph \\ node dissection is needed.}

pure-solid nodules that have had mediastinal lymph node metastasis were reported previously. ${ }^{4}$ In addition, the prevalence of lymphatic metastasis is always low for subsolid malignancies, especially if there is no lymphatic metastasis for GGO-predominant tumors. ${ }^{5}$ However, in this study, there were $9 \%(11 / 126) \mathrm{N} 1 / \mathrm{N} 2$ metastases for solid-predominant lung cancers. The lymphatic metastasis rate of $9 \%$ is not a rare event, and more invasive surgical extent, including systemic lymph node dissection, is still necessary for solid-predominant tumors. Further studies should focus on these tumors with lymph node metastasis, because once the lymph nodes are involved, the GGO component may not be a favorable prognostic factor according to our unpublished data. The predictors for lymphatic metastasis and pattern of lymphatic metastasis need to be investigated. 